\title{
Vegetable Plucking Machine Using Object Detection : A Case Study
}

doi : https://doi.org/10.32628/CSEIT217272

\section{Gopal Sakarkar, Rashmi Baitule}

Assistant Professor, Department of Artificial Intelligence, G. H. Raisoni College of Engineering, Nagpur, Maharashtra, India

\section{Article Info \\ Volume 7, Issue 2 \\ Page Number : 501-508}

Publication Issue :

March-April-2021

\section{Article History}

Accepted : 20 April 2021

Published : 25 April 2021

\begin{abstract}
Automated or robot-assisted collection is an evolving research domain that mixes aspects of machine vision and machine intelligence. When combined with robotics, image processing has proven to be an efficient method for analysis in various performance areas, namely agricultural applications. Most of it had been applied to the robot, which may want to pick fruit and type various fruits and vegetables. Identification and classification could even be a serious obstacle to computer vision demanding near-human levels of recognition. The target of this survey is to classify and briefly review the literature on harvesting robots that use different techniques and computer analysis of images of fruits and vegetables in agricultural activities, which incorporates 25 articles published within the last three decades. The proposed approach takes under consideration various sorts of fruit. Much research on this subject has been conducted in recent years, either implementing simple techniques such as computer vision like color-based clustering or using other sensors like LWIR, hyperspectral, or 3D. Current advances in computer vision offer an honest sort of advanced object detection techniques that would dramatically increase the quality of efficiency of fruit detection from RGB images. Some performance evaluation metrics obtained in various experiments are emphasized for the revised techniques, thus helping researchers to settle on and make new computer vision applications in fruit images.
\end{abstract}

Keywords : Component, Formatting, Style, Styling, Insert

\section{INTRODUCTION}

The Brief Introduction on earlier papers associated with agriculture Harvesting Robots which detects the different kinds of fruits\vegetables and plucks them based on certain mechanisms and factors. We will briefly elaborate the previous papers and explore them. Let's consider Fruit Harvesting Robot which uses a mechanism to detect capsicum(sweet pepper) by computer vision based on colour RGB featuring an analysis shape related to features of object by image plane and 3D space using a challenging capsicum dataset with significant degree of occlusion[34].A self moving harvesting robot which implies a picking mechanism by using certain parameters like object detection that identifies strawberries and by gripper it can be plucked particularly from polytunnels, which is fully automated robot which can automatically detect, pluck and pick the 
strawberries[35]. Although we know of the past few years, much research is underway on this topic. Basically we are using computer vision techniques, such as color-based segmentation or resorting to different types of sensors, such as LWIR, hyperspectral or 3D. In addition, we are implementing detection of strawberry and apple fruit using RGB images and an improved categorization framework based on improved waterfalls and image filters for applications, so we developed a great benefit in automated harvesting and crop estimation [36].

We discussed somewhat similar techniques like computer vision etc. There are some more techniques by which we can implement the paper topic. A machine vision that is capable for detecting, plucking the fruits, basically oranges. In this study they used the system which composed of six-degree of freedom(6-DOF), robotic arm, ZED stereo Camera, electric kart, image processing, visual studio and opencv library etc[37]. A computer vision for the automatic fruit harvesting robot sets out the art and the challenges ahead. Extensive research into machine vision for automatic harvesting robots that were successively made for agrobotics remains a limitation. There are so many articles that show the exhaustive review of the classic and avant-garde artificial vision solutions used in such systems, the visual signals and the machine algorithm used, still a job to obtain a solution to solve agro botanical problems.[38].A robot is no longer strictly limited to industrial environments as well as for outdoor activities, a automated robot systems are rapidly increasing in a agrobotics, combined with a new technologies and approaches to automate labour intensive work. A huge problem behind a labour intensive work is a high cost that lacks many problems to an owner or we can say a farmer.For reducing this problem we can place a robot for agricultural farms which does the all task a farmer wants, a robot is a machine which acts like a human in any whether and does the same work as human does and it is capable of doing every major tasks in a less time and by this a labour issue will be overcome for a farmer[39].

\section{LITERATURE REVIEW}

There is approximately half a century of announced research on the mechanization of the crop of Capsicum cultivars. Agriculture, despite being one of the most essential fields for humanity, as it provides food resources, has not been disturbed by automation as much as other fields and still, most of the yield is harvested by hand, supplanting the production to places where labor costs are low. low. The industrialization of the pepper harvest (or just pepper in Great Britain and also in the US) would require a systems approach that integrates research in plant breeding, production exercises and the design of harvesting machinery and plant processing. Cultivars need to be nominated for a set of fruits with a high determining factor, low accessory strength and greater resistance of the organic product divider. Harvesting machinery needs to be developed especially aggressively and capable of removing almost all fruit and gentle enough to reduce damage. Fully motorized harvesting would be feasible to every part of the system anywhere. In this review, the following previous attempts are analyzed to repeat the previous achievement and then to analyze some of the important barriers that limit the performance of autonomous pepper harvesting systems. Certainly, some of the current or past efforts around the world in automatic fruit and vegetable harvesting that could reaffirm current bottlenecks are examined.

As determined, a portion of researchers have examined modern methodologies to identify fruits and vegetables at plants utilizing various approaches such in the process of video processing 
and acquire too explained structures that can clutch or isolate the same. The first-ever publication to examine the same was in the period of 1995 (Kondo, N. et al. 1995) [1]. In view of this paper, the writer introduces a novel concept to analyze tomatoes in plants using a few visual sensors and as to pluck the same using clout cups attached to a machine. Sadly, no again explanation on how to accomplish the same has been amplified. In (Gotou, K. et al. 2003) [2] a finalize information of self-moving tomato recognition on plants using a routine laser and a cardinal laser has been characterized.

The setup is tough and accurate proves logically cost- effective. (Yang, L. et al. 2007; Kundu, S. et al. 2012; Hongpeng Yin et al. 2009)[3]-[5] make use of image processing techniques and stereo camcorder to identify tomatoes but involve problematic and tedious methods like principal factor inquiry and K-Means clustering, which taper off the entire process. A few other analysis works exist which comprises with the identification of oranges (Cakir, Y. et al. 2013)[6], pomegranates (Akin, C. et al. 2012)[7] and the eggplant (Jian Song 2010)[8] but use approaches not relevant to this project. Several technique to analyze tomatoes in controlled surroundings within companies on conveyor belts also is needed(Gejima, Y et al. 2003; GuoFeng et al. 2004; D Amato et al. 2011)[9]-[11], but can't be apply since these methods do not address the obstacle of intervention of leaves, stems and alternative surroundings factors. It should likewise be noticed that all the papers referenced above arrangement exclusively with the identification of ready natural products, thus, helping in gathering, while our extent of research lies in the way that recognition must be done at the unripe stages itself. Also, there is a finite amount of conversation on the identification of pests and also especially the borer insect.
In the previous 1960s, the conception of a selfmoving grower was proposed and inspected by Schertz and Brown [12] using a self-moving machine picking setup. They proposed a setup that uses a robotic arm to position a controller within the ace's range of bull's-eye fruit before detaching the fruit from the tree. The guidance for the controller is resolved by a machine vision setup to analyze the area of the fruit. Nonetheless, the nature of the agricultural surroundings makes fruit detection a challenging task. It is familiar that robust solutions are still broadly undeveloped. The issues are multifactor of such as the unordered surroundings, circumspection of the sensors, and a tough methodology.

Throughout the previous scarcely any decades, researchers all over the world have been trying to develop automatic reaping machines for various fruits and crops. Self-governing reaping has been determine a variety of agriculture crops like sweet peppers (Hemming et al. 2014; Bontsema et al. 2014)[13]-[14], cucumbers (Henten \& Hemming 2002)[15], citrus fruits (Mehta \& Burks2014)[16], strawberries (Hayashi et al. 2010)[17] and apples (Bulanon \& Kataoka 2010; De-An et al. 2011)[18][19].

Self-moving sweet pepper harvesting instrument has been approved by the Clever Robots for (CROPS) venture (Hemming et al. 2014; Bontsema et al. 2014)[13]-[14]. The CROPS stage accomplished a procuring achievement pace of $6 \%$ for unmodified yields and 33\% when blocking leaves and gathering bundles were evacuated. Their gain of a living features the impediment and multifaceted nature of the harvesting issue. This work shows that there is still further research and development required to solve the challenges associated with the robotic harvesting of sweet peppers. 
Detection and subdivision are extremely important to know the approximate field of the crop within an image as well as techniques have been made for both self-moving reaping and yield estimation (McCool et al. 2016; Perez et al. 2015)[20]- [21]. A common technique for robotic crop harvesting is to perform crop detection and subdivision using 3D information (position, direction, and shape) using sensors such as a structured-light camera (Lehnert et al. 2016)[22] or stereovision (Henten\& Hemming 2002)[15]. This 3D localization step also can be used to determine a clutch and fragment pose. Clasp locations can be determined by using prior geometric models fitted to the 3D scene or by using a heuristic to rank local surface information of the segmented 3D crop (Lehnert et al. 2016; Lehnert et al. 2017; Sa et al. 2016)[22][23]-[24].

A range of controller arrangement moldy used for self- moving reaping projects along with 3DOF Cartesian, anthropomorphous arms and 6DOF controller (C. W. Bac et al. 2014)[25]. Respective works have compared various intersection arrangements to optimize destination-reachability in cluttered environments (Van Henten et al. 2009; Lehnert et al. 2015)[26]-[27].

One of the key components of an autonomous robotic reaping setup is the reaping end-effector that grasps the vegetables or crops. A common solution is to use suction cups having a common gripping mechanism (Hayashi et al. 2010; Van Henten et al. 2003)[17]-[28] usually because of their mechanical simplicity and minimal surface area required to access a single bare face of the yield. One more captivating substitute is contactbased captivators (De-An et al. 2011; Ling et al. 2005)[19]-[29] normally utilize automatic fingers like grippers that close around the harvest. Contact-based captivators capab;e of holding the harvest safely however are increasingly inclined to obstruct from close by items, for example, branches, leaves and different yields. A few yields, for example, sweet pepper and cucumber should also plucked from the plant thus require an extra separation device, for example, a thermal cutter (Henten\& Hemming 2002)[15]or scissor-like mechanism (Hemming et al. 2014; Hayashi et al. 2010; Han et al. 2012)[13]-[17]-[30]. End effectors modified to a specific yield are normal, for eg. in Hemming et al. 2014 made a custom reaping tool that simultaneously surrounds and cuts-free sweet peppers with hinged jaw machinery. This working was seen more useful than the scissor mechanism, however, size and geometry requirement limited access to some sweet peppers (Hemming et al. 2014)[13].

Bachche et al. [31], Bachche et al. [32] and Bachche and Oka [33] evolve a thermal fragment setup for sweet pepper reaping machines depending on current and intensity potentiality (Fig. 1.). These setups help to escape virus renewal, curtail the fungal susceptibility and increase the shelf life of fruits by adapting a thermal cutting method. The structure for the most part comprises two equal gripper bars mounted on an edge associated by an uncommonly planned score plate and worked by a servomotor. Depend on current and power supply parameters, two unique kinds of warm cutting arrangement models-i.e., temperature arc and electric arc. Basically the electric arc is an electric device which provides high power supply and performs the cutting activity. At the degree of higher voltage, terminals produce a warm curve, which assists with cutting the stem of sweet peppers. On the second hand the temperature arc and nichrome wires are placed on two electrodes and current is supplied to this electrodes. This process results in the formation of a high temperature arc between these two electrodes that helps us to perform cutting operations. In addition to this, these 
prototype models are tested for defined variable fields in which the temperature arc configuration is determined to be effective. These models take 1.5 seconds to complete the cutting task. Postharvest monitoring of the fruits is confirmed and the increased shelf life of the fruits leads to transformation of the fungal and virus reconstruction. Fruits are brought together using the thermal arc cut configuration and can be kept for more than 15 days in normal environments.

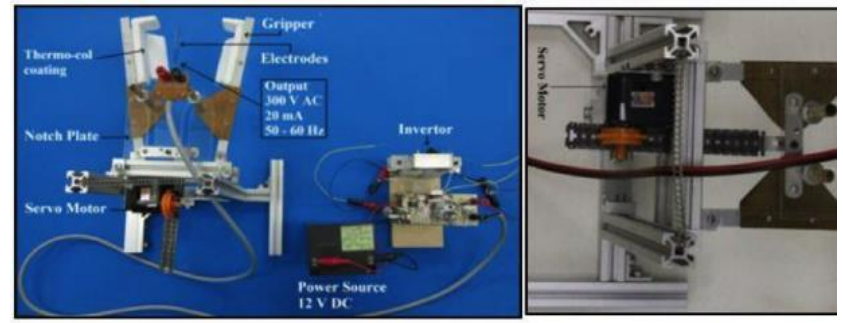

(a) Thermal Cutting System

(b) Electric Ari

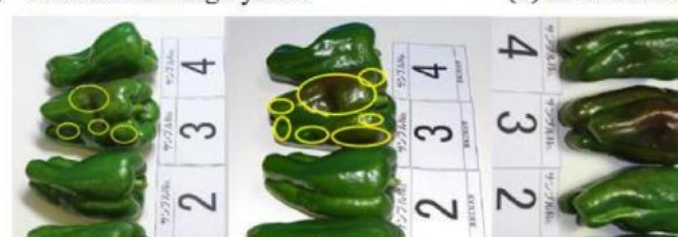

Fig. 1. Summary of thermal cutting gripper [34-36]

A. Maintaining the Integrity of the Specifications

\begin{tabular}{|c|c|c|c|c|c|c|c|}
\hline $\begin{array}{c}\text { Name of } \\
\text { Harvesting } \\
\text { Robot } \\
\text { (Manufacturing } \\
\text { duration) }\end{array}$ & $\begin{array}{l}\text { Developed } \\
\text { By/Manufact } \\
\text { ured by }\end{array}$ & $\begin{array}{l}\text { Target } \\
\text { Crops }\end{array}$ & $\begin{array}{l}\text { Work } \\
\text { ing } \\
\text { hours }\end{array}$ & $\begin{array}{l}\text { Succe } \\
\text { ss } \\
\text { Rate } \\
(\%)\end{array}$ & $\begin{array}{l}\text { Averag } \\
\text { e } \\
\text { picking } \\
\text { Time }\end{array}$ & $\begin{array}{c}\text { Expected } \\
/ \\
\text { Estimate } \\
\mathrm{d} \text { cost of } \\
\text { single } \\
\text { robot / } \\
\text { machine }\end{array}$ & Source \\
\hline $\begin{array}{l}\text { FFRobot (2014- } \\
\text { 2019) }\end{array}$ & $\begin{array}{c}\text { FFRobotics } \\
\text { (Fresh Fruit } \\
\text { Robotic } \\
\text { Harvest) }\end{array}$ & Apples & $24 / 7$ & $\begin{array}{l}85- \\
96 \%\end{array}$ & $\begin{array}{c}10,000 \\
\text { apples } \\
\text { per } \\
\text { hour }\end{array}$ & $\begin{array}{c}\$ 300,000 \\
- \\
\$ 350,000\end{array}$ & https://kutt.it/HYTRVt \\
\hline $\begin{array}{c}\text { Harvey } \\
(2013-2017)\end{array}$ & $\begin{array}{l}\text { Queensland } \\
\text { University } \\
\text { of } \\
\text { Technology } \\
\text { (QUT) }\end{array}$ & $\begin{array}{c}\text { Sweet } \\
\text { Pepper } \\
\text { s } \\
\text { (Capsic } \\
\text { um) } \\
\end{array}$ & $\begin{array}{c}8 \\
\text { hours }\end{array}$ & $76.5 \%$ & $30 \mathrm{sec}$ & & https://kutt.it/JRHTGo \\
\hline $\begin{array}{c}\text { Sweeper } \\
(2015-2018)\end{array}$ & $\begin{array}{c}\text { Wageningen } \\
\text { University \& } \\
\text { Research }\end{array}$ & $\begin{array}{c}\text { Sweet } \\
\text { Pepper } \\
\text { S } \\
\text { (Capsic } \\
\text { um) }\end{array}$ & $\begin{array}{c}20 \\
\text { hours }\end{array}$ & $62 \%$ & $24 \mathrm{sec}$ & $\begin{array}{c}75,000- \\
100,000 \\
\text { euro }\end{array}$ & $\frac{\underline{\text { https://kutt.it/wMu90 }}}{\underline{\mathrm{G}}}$ \\
\hline $\begin{array}{c}\text { Rubion } \\
(2014-2019)\end{array}$ & Octinion & $\begin{array}{l}\text { Strawb } \\
\text { erry }\end{array}$ & $\begin{array}{c}8 \\
\text { hours }\end{array}$ & $\begin{array}{c}70- \\
95 \%\end{array}$ & $5 \mathrm{sec}$ & $\begin{array}{c}100,000- \\
150,000 \\
\text { euro }\end{array}$ & $\frac{\text { https://kutt.it/4KwGL }}{\underline{\mathrm{O}}}$ \\
\hline $\begin{array}{l}\text { Agrobot E- } \\
\text { Series }\end{array}$ & Agrobot & $\begin{array}{l}\text { Strawb } \\
\text { erry }\end{array}$ & $\begin{array}{c}24 \\
\text { hours }\end{array}$ & & $4 \mathrm{sec}$ & $\$ 250,000$ & $\frac{\underline{\text { https://www.agrobot.c }}}{\underline{\mathrm{om} /}}$ \\
\hline
\end{tabular}

\section{CONCLUSION}

Therefore, we have discussed background papers based on Artificial Intelligence and Machine
Learning and Agriculture based machine harvesting robots. We discuss and present each document that shows various kinds of methods that will solve 
agricultural problems, and the Artificial Intelligence and Machine Learning Technique offers the best technology that can detect various kinds of vegetables and fruits and a machine that walks like a human being and collects the Vegetable is nothing but a robot. In this way, we can solve the concept of labor with a robot that acts like a human on farms and adapts to all the facilities that humans do on the farm to cultivate. Therefore, we know that a machine can learn and analyze and does work like a human does on a farm for cultivation.

\section{ACKNOWLEDGMENT}

G. H. Raisoni University in Saikheda, we discussed our project titled as "Vegetable Plucking Machine with Object Detection: A Case Study". We have understood the problem of the farmers that how much it is difficult to pluck each and every vegetables from the plants thus it becomes a very tedious task. So we are giving a solution as a robot that will pluck automatically by morphological characteristics and colour filtering mechanism, Under the grant AI for Earth, AI for earth is an Microsoft program aimed at empowering people and organization to achieve global environmental challenges by increasing access to AI tools and educational opportunities, while accelerating innovations.

\section{REFERENCES}

[1]. G. Kondo, N.; Monta, M.; Fujiura, T.; Shibano, Y., "Intelligent Robot to Harvest Tomato," Robotics and Automation, 1995. Proceedings., 1995 IEEE International Conference on , vol.3, no., pp.V19,, 21-27 May 1995.

[2]. Gotou, K.; Fujiura, T.; Nishiura, Y.; Ikeda, H.; Dohi, M., "3-D vision system of tomato production robot," Advanced Intelligent Mechatronics, 2003. AIM 2003. Proceedings.
2003 IEEE/ASME International Conference on , vol.2, no., pp.1210,1215 vol.2, 20-24 July 2003.

[3]. Yang, L.; Dickinson, J.; Wu, Q. M J; Lang, S., "A fruit recognition method for automatic harvesting," Mechatronics and Machine Vision in Practice, 2007. M2VIP 2007. 14th International Conference on , vol., no., pp.152,157, 4-6 Dec. 2007.

[4]. Kundu, S.; Hazra, A; Deb, K.; Hazra, P., "Dimensionality reduction of morphological features of tomato leaves and fruiting habits," Communications, Devices and Intelligent Systems (CODIS), 2012 International Conference on , vol., no., pp.608,611, 28-29 Dec. 2012.

[5]. Hongpeng Yin; Yi Chai; Yang, Simon X.; Mittal, G.S., "Ripe tomato extraction for a harvesting robotic system," Systems, Man and Cybernetics, 2009. SMC 2009. IEEE International Conference on , vol., no., pp.2984,2989, 11-14 Oct. 2009.

[6]. Cakir, Y.; Kirci, M.; Gunes, E.O.; Ustundag, B.B., "Detection of oranges in outdoor conditions," Agro-Geoinformatics (Agro- Geoinformatics), 2013 Second International Conference on , vol., no., pp.500,503, 12-16 Aug. 2013.

[7]. Akin, C.; Kirci, M.; Gunes, E.O.; Cakir, Y., "Detection of the pomegranate fruits on tree using image processing," Agro- Geoinformatics (Agro-Geoinformatics), 2012 First International Conference on, vol., no., pp.1,4, 2-4 Aug. 2012.

[8]. Jian Song, "Target identification based on automatic threshold for eggplant picking robot," Information Science and Engineering (ICISE), 2010 2nd International Conference on , vol., no., pp.1567,1569, 4-6 Dec. 2010.

[9]. Gejima, Y.; Houguo Zhang; Nagata, M., "Judgment on level of maturity for tomato quality using L*a*b* color image processing," Advanced Intelligent Mechatronics, 2003. AIM 2003. Proceedings. 2003 IEEE/ASME International Conference on , vol.2, no., pp.1355,1359 vol.2, 20-24 July 2003.

[10]. GuoFeng; Cao Qixin, "Study on color image processing based intelligent fruit sorting system," 
Intelligent Control and Automation, 2004. WCICA 2004. Fifth World Congress on , vol.6, no., pp.4802,4805 Vol.6, 15-19 June 2004.

[11]. D Amato, Juan Pablo; Garcia Bauza, Cristian; Boroni, Gustavo, "Color Based Fruits classification using GPU," Latin America Transactions, IEEE (Revista IEEE America Latina), vol.9, no.3, pp.346,350, June 2011.

[12]. Schertz C E ; Brown G K, Basic considerations in mechanizing citrus harvest, Transaction of the ASAE, 1968, pp.343-346.

[13]. J. Hemming, C. Bac, B. van Tuijl, R. Barth, J. Bontsema, E. Pekkeriet, and E. van Henten, "A robot for harvesting sweet-pepper in greenhouses," in Proceedings of the International Conference of Agricultural Engineering, Jul. 2014.

[14]. J. Bontsema, J. Hemming, E. P. W. Saeys, Y. Edan, A. Shapiro, M. Ho cevar, T. Hellstr"om, R. Oberti, M. Armada, H. Ulbrich, J. Baur, B. Debilde, S. Best, S. Evain, A. M"unzenmaier, and O. Ringdahl, "CROPS: high tech agricultural robots," in International Conference of Agricultural Engineering, 2014, pp. 6-10.

[15]. E. van Henten and J. Hemming, "An autonomous robot for harvesting cucumbers in greenhouses," Autonomous Robots, pp. 241-258, 2002.

[16]. S. Mehta and T. Burks, "Vision-based control of robotic manipulator for citrus harvesting," Computers and Electronics in Agriculture, vol. 102, pp. 146-158, Mar. 2014.

[17]. S. Hayashi, K. Shigematsu, S. Yamamoto, K. Kobayashi, Y. Kohno, J. Kamata, and M. Kurita, "Evaluation of a strawberry-harvesting robot in a field test," Biosystems Engineering, vol. 105(2), pp. 160-171, 2010.

[18]. D. Bulanon and T. Kataoka, "Fruit detection system and an end effector for robotic harvesting of fuji apples," Agricultural Engineering International: CIGR Journal, vol. 12, no. 1, 2010.

[19]. Z. De-An, L. Jidong, J. Wei, Z. Ying, and C. Yu, "Design and control of an apple harvesting robot," Biosystems engineering, 2011.
[20]. C. McCool, I. Sa, F. Dayoub, C. Lehnert, T. Perez, and B. Upcroft, "Visual Detection of Occluded Crop: for automated harvesting," in IEEE International Conference on Robotics and Automation (ICRA), 2016.

[21]. Perez, T., Sa, I., McCool, C. andLehnert, C. (2015). "A bayesian framework for the assessment of vision-based weed and fruit detection and classification algorithms" . In,2015 IEEE International Conference on Robotics and Automation (ICRA). IEEE,Seattle, WA.

[22]. Lehnert $C$ et al., 2016. Sweet pepper pose detection and grasping for automated crop harvesting. In: IEEE International Conference on Robotics and Automation. Pp. 2428-2434.

[23]. Lehnert C, English A, McCool C, Tow AW, Perez T. "Autonomous sweet pepper harvesting for protected cropping systems". IEEE Robot AutomLett 2017; 2(2): 1-8.

[24]. I. Sa, C. Lehnert, A. English, C. Mccool, T. Perez, and B. Upcroft, "Sweet pepper peduncle detection for autonomous crop harvesting," IEEE Robotics and Automation Letters, 2016.

[25]. C. W. Bac, E. J. van Henten, J. Hemming, and Y. Edan, "Harvesting Robots for High-value Crops: State-of-the-art Review and Challenges Ahead," Journal of Field Robotics, 2014.

[26]. E. J. Van Henten, D. a. Van't Slot, C. W. J. Hol, and L. G. Van Willigenburg, "Optimal manipulator design for a cucumber harvesting robot," Computers and Electronics in Agriculture, vol. 65, no. 2, pp. 247-257, 2009.

[27]. C. Lehnert, T. Perez, and C. McCool, "Optimisation-based Design of a Manipulator for Harvesting Capsicum," in IEEE International Conference on Robotics and Automation (ICRA) Agricultural Robotics workshop, 2015.

[28]. E. Van Henten, B. Van Tuijl, J. Hemming, J. Kornet, J. Bontsema, andE. Van Os, "Field Test of an Autonomous Cucumber Picking Robot," Biosystems Engineering, vol. 86, no. 3, pp. 305313, nov 2003. 
[29]. P. Ling, R. Ehsani, K. C. Ting, N. Ramalingam, M. H. Klingman, Y.-T. Chi, and C. Draper, "Sensing and end-effector for a robotic tomato harvester," ASAE Annual Meeting, vol. 12, 2004.

[30]. K.-S. Han, S.-C. Kim, Y.-B. Lee, S.-C. Kim, D.-H. Im, H.-K. Choi, and

[31]. H. Hwang, "Strawberry harvesting robot for bench-type cultivation," Biosystems Engineering, vol. 37, pp. 65-74, 2012.

[32]. Bachche, S.; Oka, K.; Sakamoto, H. Development of thermal cutting system for sweet pepper harvesting robot in greenhouse horticulture. In Proceedings of the JSME Conference on Robotics and Mechatronics, Hamamatsu, Japan, 27-29 May 2012.

[33]. Bachche, S.; Oka, K.; Sakamoto, H. Development of current based temperature arc thermal cutting system for green pepper harvesting robot. In Proceedings of the Shikoku-section Joint Convention of the Institute of Electrical and related Engineers, Takamatsu, Japan, 29 September 2012.

[34]. Bachche, S.; Oka, K. Performance testing of thermal cutting system for sweet pepper harvesting robot in greenhouse horticulture J. Syst. Des. Dyn. 2013, 7, 36-51.

[35]. E. Barnea, R. Mairon, and O. Ben-Shahar, "Colour-agnostic shape-based 3d fruitdetection for crop harvesting robots,"Biosystems Engineering, vol. 146, pp. 57-70, 2016.

[36]. Xiong, Y. Ge, L. Grimstad, and P. J. From, "An autonomous strawberry-harvesting robot: Design, development, integration, and field evaluation,"Journalof Field Robotics, vol. 37, no. 2, pp. 202-224, 2020.

[37]. S. Puttemans, Y. Vanbrabant, L. Tits, and T. Goedem'e, "Automated visual fruit de-tection for harvest estimation and robotic harvesting," in2016 Sixth InternationalConference on Image Processing Theory, Tools and Applications (IPTA).IEEE,2016.

[38]. K. A. M. Almendral, R. M. G. Babaran, B. J. C. Carzon, K. P. K. Cu, J.
[39]. M. Lalanto,and A. C. Abad, "Autonomous fruit harvester with machine vision,"Journal ofTelecommunication, Electronic and Computer Engineering (JTEC), vol. 10, no.1-6, pp. 79-86, 2018.

[40]. K. Kapach, E. Barnea, R. Mairon, Y. Edan, and O. Ben-Shahar, "Computer visionfor fruit harvesting robots-state of the art and challenges ahead,"InternationalJournal of Computational Vision and Robotics, vol. 3, no. 1/2, pp. 4-34, 2012.

[41]. J. Baeten, K. Donn' e, S. Boedrij, W. Beckers, and E. Claesen, "Autonomousfruit picking machine: A robotic apple harvester," inField and service robotics.Springer, 2008, pp. 531-539.

\section{Cite this article as :}

Gopal Sakarkar, Rashmi Baitule, "Vegetable Plucking Machine Using Object Detection : A Case Study", International Journal of Scientific Research in Computer Science, Engineering and Information Technology (IJSRCSEIT), ISSN : 2456-3307, Volume 7 Issue 2, pp. 501-508, March-April 2021. Available at doi : https://doi.org/10.32628/CSEIT217272 Journal URL : https://ijsrcseit.com/CSEIT217272 